\title{
Safety of Cranberry: Evaluation of Evidence of Kidney Stone Formation and Botanical Drug-Interactions"
}

Authors

Emily Madden ${ }^{1}$, Caleb McLachlan ${ }^{2}$, Hellen Oketch-Rabah ${ }^{1}{ }^{\mathbb{D}}$, Angela I. Calderón $^{2,3}$

\section{Affiliations}

1 United States Pharmacopeial Convention, Rockville, MD

2 Department of Drug Discovery and Development, Harrison School of Pharmacy, Auburn University, Auburn, AL

3 United States Pharmacopeia Botanical Dietary Supplements and Herbal Medicines Expert Committee, Rockville, MD

Key words

cranberry, dietary supplement interactions, kidney stone safety, warfarin, urinary tract infection, Ericaceae

\section{received}

February 2, 2021

accepted after revision

May 1, 2021

published online

May 20, 2021

Bibliography

Planta Med 2021; 87: 803-817

DOI 10.1055/a-1497-6241

ISSN 0032-0943

(c) 2021. Thieme. All rights reserved.

Georg Thieme Verlag KG, Rüdigerstraße 14,

70469 Stuttgart, Germany

Correspondence

Emily Madden, Ph.D., D.A.B.T.

United States Pharmacopeia, DSHM

12601 Twinbrook Pkwy, 20852 Rockville, MD, USA

Phone: + 130181682 98, Fax: + 13018168182

emily.madden@usp.org

Correspondence

Angela I Calderón, Ph.D.

Department of Drug Discovery and Development,

Harrison School of Pharmacy, Auburn University

3306 Walker Building, 36849 Auburn, AL, USA

Phone: + 13348448333 , Fax: + 13348448331

aic0001@auburn.edu

\section{ABSTRACT}

Cranberry is a popular ingredient in dietary supplements in the U.S. and is commonly used for preventing urinary tract infections. Because of its popularity in dietary supplements, the U.S. Pharmacopeial Convention has developed quality standards for cranberry ingredients. The purpose of this review was to determine if there are safety issues that should preclude the admission of cranberry ingredients from the development of U.S. Pharmacopeial Convention quality standards. Based on the totality of the data, the U.S. Pharmacopeial Convention concluded that cranberry ingredients are not known to be associated with serious risks to human health when consumed properly in dietary supplements and therefore were admitted for standard development. Although published clinical and animal data indicated that cranberry is not associated with serious adverse effects, interactions with warfarin and kidney stone formation were identified as potential risks. Studies have reported contradictory data regarding the role of cranberry in kidney stone formation, with some reports suggesting cranberry is associated with a reduced risk of kidney stones. Interactions with warfarin were not associated with moderate intakes of cranberry juice (240-480 mL). Some reports suggested that the potential for warfarin interactions requires excessive intakes of cranberry juice (1-2 L/day) or cranberry extracts (3000 mg/day). Cases of warfarin interactions with cranberry have mostly involved patients with serious illnesses and/or individuals taking concomitant medications. Based on these findings, the U.S. Pharmacopeial Convention concluded that the use of cautionary labeling statements regarding interactions with warfarin or kidney stone formation is not necessary in the development of quality standards for cranberry ingredients.

\# Dedicated to Professor Arnold Vlietinck on the occasion of his 80th birthday. 


$\begin{array}{ll}\text { ABBREVIATIONS } \\ \text { AE } & \text { adverse event } \\ \text { AER } & \text { adverse event report } \\ \text { AHPA } & \text { American Herbal Products Association } \\ \text { ANSES } & \text { French Agency for Food, Environmental and } \\ & \text { Occupational Health \& Safety } \\ \text { CAERS } & \text { Center for Food Safety and Applied Nutrition } \\ & \text { Adverse Event Reporting System } \\ \text { CSR } & \text { Cochrane systematic review } \\ \text { DAEN } & \text { Database of Adverse Events Notifications } \\ \text { DS } & \text { dietary supplements } \\ \text { DSHEA } & \text { Dietary Supplement Health and Education Act } \\ \text { EFSA } & \text { European Food Safety Authority } \\ \text { EMA } & \text { European Medicines Agency } \\ \text { FDA } & \text { U.S. Food and Drug Administration } \\ \text { GRAS } & \text { generally recognized as safe } \\ \text { GRN } & \text { generally recognized as safe notice } \\ \text { HDL } & \text { high-density lipoprotein } \\ \text { INR } & \text { international normalized ratio } \\ \text { LDL } & \text { low-density lipoprotein } \\ \text { LNHPD } & \text { Licensed Natural Health Products Database } \\ \text { MHRA } & \text { Medicines and Healthcare Products Regulatory } \\ & \text { Agency } \\ \text { NDI } & \text { New Dietary Ingredient } \\ \text { NDIN } & \text { New Dietary Ingredient Notification } \\ \text { NHPID } & \text { Natural Health Products Ingredients Database } \\ \text { NIH } & \text { National Institutes of Health } \\ \text { PACs } & \text { proanthocyanidins } \\ \text { TGA } & \text { Therapeutic Goods Administration } \\ \text { USDA } & \text { U.S. Department of Agriculture } \\ \text { USP } & \text { U.S. Pharmacopeial Convention } \\ \text { UTI } & \text { urinary tract infection } \\ & \end{array}$

\section{Introduction}

Cranberry (Vaccinium macrocarpon Aiton) is a fruit native to North America [1,2]. Cranberry was of importance to Native Americans in their diet, in commerce, and for its medicinal properties [3]. Cranberry was used by Native Americans in a variety of foods, for dyeing rugs and blankets, and for treating wounds [2].

There is a long history of scientific research on cranberry as an herbal remedy, dating back to its chemical characterization in the late 19th century as described by Raz et al. [4]. It was long believed that cranberries had medicinal properties related to the bladder and kidneys due to urine acidification. German physicians determined that after the ingestion of cranberries, urinary excretion of hippuric acid levels increased. Subsequent research confirmed this phenomenon and attributed it to the benzoic acid found in cranberries. The theory postulated that the benzoic acid was being converted into hippuric acid in vivo and thus lowered the $\mathrm{pH}$ of urine. For a while after, researchers claimed that the production of hippuric acid was enough to be considered bacteriostatic [4]. However, a 1959 article published by Bodel et al. [5] showed that cranberries were not a rich enough source of benzoic acid for the resulting hippuric acid to be bacteriostatic.
The actual mechanism behind cranberries' medicinal properties for the kidney and bladder involve preventing microbial adhesion. This mechanism is attributed to PACs, specifically proanthocyanidin-A found in cranberry, which exhibits potent in vitro antiadhesion bioactivity $[2,6-8]$ and is thought to be responsible for interfering with bacterial adhesion to the epithelial cells of the urinary tract [9]. This is why cranberry products are largely used today to prevent UTIs although persuasive clinical evidence is still lacking [10].

Within the past 25 years, research on cranberry has progressed from its prevention of UTIs to its effects on cardiovascular risk factors, metabolic syndrome, gut microbiota, and cancer prevention [10]. Cranberry and its phytochemicals are suggested to have anticancer properties [11] and protective effects against vascular diseases [10]. The impact of cranberry on intestinal health has also been investigated, but most data is from animal models and in vitro studies. While cranberry extract can alter the microbial composition in the gut of mice, the effects of cranberry on gut microbiota in humans are unknown [10]. The Philip E. Marucci Center for Blueberry and Cranberry Research has a program that conducts research on the health benefits of cranberry in the prevention and management of bacterial diseases, including UTIs, stomach ulcers, and periodontal disease [12].

In 2019, cranberry supplement products were the 5th bestselling supplements in U.S. mainstream retail outlets (\$88900064.38) and the 12th best-selling supplements in U.S. natural and health food specialty retail outlets (\$7919630.81 in total sales) [13]. Given the popularity of cranberry as a dietary ingredient in DS, the USP has developed quality standards for cranberry ingredients. USP is an independent, nonprofit, sciencebased organization that sets public quality standards for medicines, foods, and DS. In setting standards for DS, USP recognized that although manufacturers and suppliers of NDIs may be required to submit an NDIN containing data on identity, manufacturing, toxicology, and safety to the U.S. FDA before the DS can be legally introduced into the market, there is no notification for many dietary ingredients, either because they were marketed in DS before 1994 (pre-dating the DSHEA and are therefore not classified as NDIs) or because they are NDIs for which a notification is not required under the law (i.e., when the NDI and all other dietary ingredients in the DS have been present in the food supply as articles used for food in a form in which the food has not been chemically altered) [14]. Consequently, these ingredients may not have undergone a thorough safety evaluation.

In recognizing this gap, USP instituted the USP Dietary Supplements Admission Evaluation, a process to evaluate articles for safety concerns before developing a monograph outlining quality for a dietary supplement or dietary ingredient. The process includes a comprehensive assessment of publicly available evidence conducted by the USP Dietary Supplements Admission Evaluations Joint Standard Setting Subcommittee (DSAE JS3) to help ensure that a dietary ingredient does not present serious health risk to public health [15]. This evaluation of cranberry ingredients was conducted according to USP guidelines for the admission of DS ingredients into the monograph development process [16] and included an assessment to ascertain whether cranberry ingredients present a severe risk to human health. This comprehensive review 


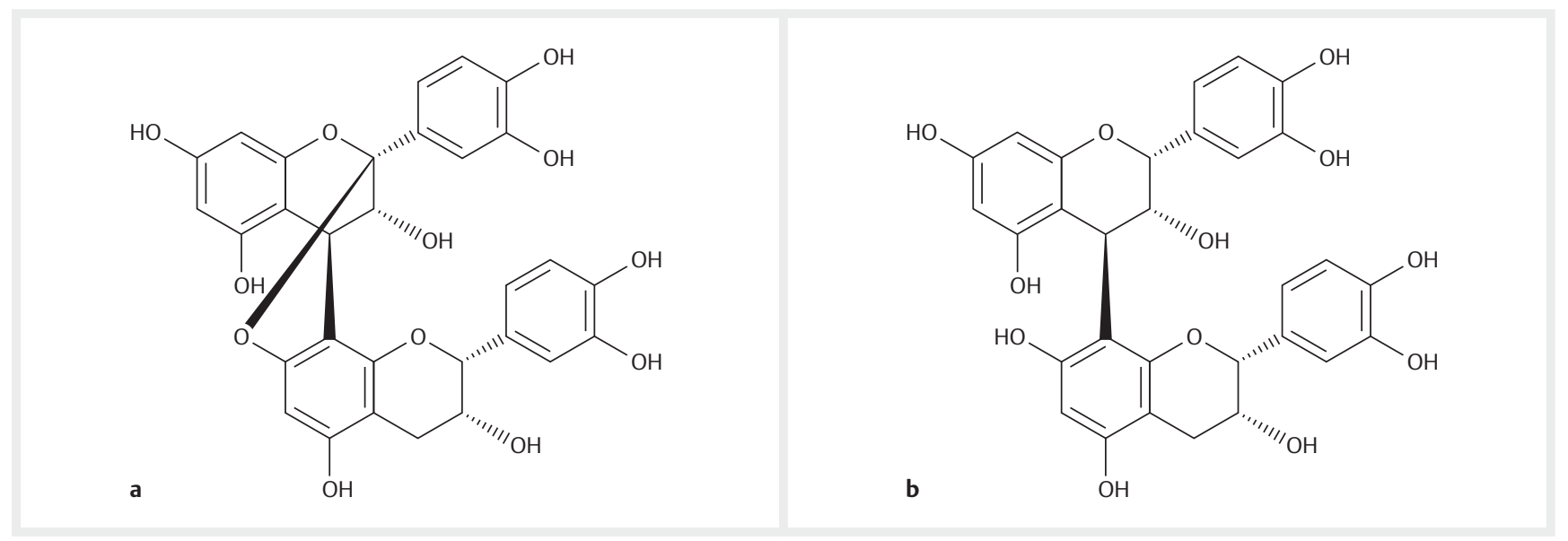

- Fig. 1 Structures of A-type (a) and B-type (b) proanthocyanidins (PACs).

provided the data to determine whether cranberry ingredients could be admitted to the USP monograph development process. In this review, the safety of cranberry as a dietary ingredient was assessed with a specific focus on kidney stone formation and drug-herbal interactions with warfarin. Unless otherwise stated, throughout this article "cranberry" refers to the cranberry fruit.

\section{Literature Search Method}

To find relevant safety information, the literature search focused on articles about cranberry phytochemicals, clinical trials involving cranberry preparations or their constituents, potential interactions of constituents, and studies on toxicology (in vitro and in vivo). Initial searches were conducted in PubMed by using the keywords "Cranberry", "Cranberry fruit", or "Vaccinium macrocarpon", combined with terms such as "safety", "phytochemicals", "clinical studies", "adverse events", "drug interactions", "animal studies", and "in vitro" (earliest to 2020). During this review, kidney stone formation and interactions with warfarin were identified as potential adverse effects of cranberry consumption; therefore, an additional search was performed using the keywords described above and the terms "kidney stone" and "warfarin interactions". Additional electronic databases that were used in the literature search included Google Scholar, TOXLINE, ScienceDirect, and The Cochrane Library (earliest to 2020). Subsequent publications were identified by searching the reference lists of relevant journal publications and books. Additionally, texts about herbal ingredient safety were used in this review for cranberry (e.g., AHPA Botanical Safety Handbook) [17].

\section{Cranberry Phytochemistry and Pharmacopeial Quality}

Although they are composed of $88 \%$ water, cranberry is a rich source of phenolic compounds such as PACs, anthocyanins, flavonoids, and phenolic acids [18-20]. PACs are polymeric condensation products of flavan-3-ols and are commonly consumed flavo- noids in the American diet [21]. The flavan-3-ols found in cranberry exist as monomers, oligomers, and polymers [19]. The flavan-3-ol monomer and dimer content in cranberry is $70-330 \mu \mathrm{g} /$ $\mathrm{g}$, and the anthocyanin content is $130-1710 \mu \mathrm{g} / \mathrm{g}$ [19]. However, the anthocyanin content can vary depending on the cultivar [2, 11, 19].

Cranberry contains both A-type and B-type PACs; however, the A-type PACs are present in higher concentrations, accounting for 51-91\% of total PACs [19]. The only structural difference between A-type and B-type PACs is that A-type have an extra bond linking the top and bottom heterocycles. The structure of A-type and B-type PACs is shown in > Fig. 1. The average concentrations of PACs are $4.19 \mathrm{mg} / \mathrm{g}(0.4 \%)$ by weight in cranberry and $231 \mathrm{mg} / \mathrm{L}$ in cranberry juice $[2,22]$. Another publication reported a range of $1.33-3.67 \mathrm{mg} / \mathrm{g}$ of PACs in the fruit and $89-230 \mathrm{mg} / \mathrm{L} \mathrm{PACs}$ in the juice [19]. Five laboratories performed analyses on $11 \mathrm{com}$ mercial powdered cranberry samples and found that the PACs had a range of $0.63-177 \mathrm{mg} / \mathrm{g}$ [23]. The processing of cranberries into various products has been found to impact PAC content [24, 25]. The total flavonol content in fresh cranberry is $0.2-0.4 \mathrm{mg} / \mathrm{g}$ [2], with approximately $75 \%$ of the flavonols being quercetin glycosides [11]. The quercetin content in cranberry varies from $0.11-$ $0.25 \mathrm{mg} / \mathrm{g}$. Myricetin and kaempferol are the next most common flavonols [2]. Other cranberry constituents include triterpenoids, lectins, catechins, ascorbic acid, benzoic acid, quinic acid, oxalic acid, citric acid, and malic acid $[2,19,26]$.

Cranberry pomace is a byproduct of cranberry pressing and is composed of skin, seeds, and stems [27-29]. Pomace is a rich source of polyphenolic compounds because the skins and seeds contain high levels of these constituents [28-30]. Biochemical characterization of pomace extracts showed that they contain a broad range of polyphenols that are also present in cranberry juice concentrates [30]. The crude content of polyphenols found in cranberry pomace is $6.0 \mathrm{mg} / \mathrm{g}$ [28]. The content of total anthocyanins, flavonols, and procyanidins reported in cranberry pomace (per dry weight) is $1.214 \mathrm{mg} / \mathrm{g}, 3.584 \mathrm{mg} / \mathrm{g}$, and $1.673-$ $1.865 \mathrm{mg} / \mathrm{g}$, respectively $[28,29]$. 
This review encompasses the following proposed USP monographs in development: Cranberry Fruit Juice, Cranberry Fruit Juice Concentrate, Cranberry Fruit Juice Dry Extract, and Cranberry Fruit Dry Juice. The proposed USP monographs define these ingredients as derived from the fruits of Vaccinium macrocarpon Aiton (Ericaceae).

Cranberry fruit juice (formally cranberry liquid preparation) is defined as a bright red juice having a content of soluble solids corresponding to a refractive index of 1.3435-1.3445 and containing no added substances. Cranberry fruit juice concentrate consists of the bright red juice concentrated to a content of soluble solids corresponding to a refractive index of 1.4191-1.4212. It contains not less than (NLT) $0.6 \% \mathrm{w} / \mathrm{w}$ of total PACs, calculated as procyanidin $\mathrm{A}_{2}\left(\mathrm{C}_{30} \mathrm{H}_{24} \mathrm{O}_{12}\right)$, and contains no added substances. Cranberry fruit juice dry extract is prepared from cranberry fruit juice concentrate after hydroalcoholic extraction over an adsorbent resin. The extract contains NLT 15\% of total PACs, calculated as procyanidin $\mathrm{A}_{2}$ on an as-is basis, and it may contain suitable added substances. Cranberry fruit dry juice is obtained by drying cranberry fruit juice concentrate onto suitable carriers and anticaking agents. It contains no more than $50 \%$ suitable carriers and anti-caking agents. It contains $80-120 \%$ of the labeled amount of total PACs, calculated as procyanidin $\mathrm{A}_{2}$ on the dried basis. It also contains NLT $12 \%$ of total organic acids and $90-110 \%$ of the labeled amount of total organic acids, both calculated as the sum of quinic acid, malic acid, and citric acid on a dried basis. The ratio of quinic acid to malic acid is NLT 1 , and the ratio of quinic acid to citric acid is NLT 0.5 .

This review also considers other cranberry preparations that are planned for USP monograph development. These preparations include (1) cranberry fruit powder (whole berry, pulverized), (2) cranberry pomace powder, and (3) cranberry pomace aqueous powder. The constituents in cranberry fruit powder are the same as juice concentrate and dry juice in terms of polyphenols, organic acids, and sugars. Cranberry pomace powder and cranberry pomace aqueous powder are expected to contain much fewer polyphenols than cranberry juice and cranberry fruit-derived ingredients and no sugar or organic acids.

Cranberry preparations can be adulterated by grape skin, hibiscus, blueberry, bilberry, or peanut skin extracts [31]. One of the primary reasons for these substitutions is lower-cost sources of either anthocyanins or PACs, including grapes (Vitis vinifera) and peanuts (Arachis hypogaea) [31]. Lower-cost anthocyanin-rich extracts include Mulberry (Morus spp.) fruit, hibiscus (Hibiscus sabdariffa), calyx, black bean (Phaseolus vulgaris) skin, or black rice (Oryza sativa) [31]. The proposed USP monographs for cranberry fruit juice, cranberry fruit juice concentrate, cranberry fruit juice dry extract, and cranberry fruit dry juice include HPLC and HTLC identification tests with anti-adulteration criteria to detect the possible presence of other cyanidin sources such as hibiscus, blueberry, bilberry, or peanut skin extracts.

\section{Regulatory Status of Cranberry and Reported Intake Levels}

In the U.S., cranberry is available as an ingredient in numerous DS [32]. Cranberry powder and cranberry juice concentrate are included in the United Natural Products Alliance list of old dietary ingredients [33]. Cranberry is also listed in the AHPA's Herbs of Commerce [34]. Although the FDA does not recognize these industry lists as authoritative, the presence of cranberry on these lists suggests its use in DS on the market before the enactment of DSHEA.

Cranberry extract was the subject of an NDIN (NDIN No. 902) that was submitted in 2015 to the FDA for a cranberry extract with A-type PACs [35]. The FDA objected to the NDIN because it included a drug claim for the prevention of chronic and acute UTIs. Subsequently, the notifier submitted a new NDIN (NDIN No.918) with the drug claim removed, and the FDA expressed no further objections [36]. Information on the specifications and manufacturing method were redacted in the publicly available NDINs, limiting its use for this review.

In 1999, a crospovidone-cranberry juice extract consisting of a cranberry extract adsorbed to crospovidone was the subject of a GRN (GRN No. 30) submitted to the FDA. The FDA concluded that the notice did not provide a sufficient basis for a GRAS determination [37]. The FDA noted that GRN No. 30 did not have a comprehensive discussion of the published scientific data, which did not follow the specific recommendations of the proposed rule regarding the submission of a GRAS notice. Under the proposed rule (proposed 21 CFR 170.36[c][4][i][A]), a notifier would provide "a comprehensive discussion of, and citations to, generally available and accepted scientific data, information, methods, or principles that the notifier relies on to establish safety". In addition, the notifier stated that crospovidone is "declared GRAS" as a clarifying and stabilizing agent in beverage processing, as listed in 21 CFR 173.50 , to which the FDA responded that the assertion was incorrect, as the regulation is for a food additive and not for a GRAS affirmation. The FDA noted the acute toxicity data provided for crospovidone-cranberry juice extract was insufficient to support its safety for the amount of crospovidone that would be consumed. The FDA also noted that cranberry contains a significant amount of mutagenic phenolic compounds, including quercetin (73-250 mg/kg fresh weight), myricetin $(4.0-26.7 \mathrm{mg} / \mathrm{kg})$, and kaempferol (0-2.7 mg/kg). Quercetin, myricetin, and kaempferol were demonstrated to be mutagenic by the Ames test, and the National Toxicology Program presented evidence of carcinogenic activity (i.e., increased incidence of renal tubule cell adenomas) of quercetin in male F344/N rats [38]. The FDA remarked that GRN No. 30 did not address or contradict these findings [37]. However, the International Agency for Research on Cancer (IARC) has evaluated quercetin, which included a review of the NTP study in F344/N rats along with other available animal and human data, and the IARC concluded that there is limited evidence in experimental animals and inadequate evidence in humans for the carcinogenicity of quercetin. The IARC classified quercetin as Group 3: not classifiable as to its carcinogenicity to humans [39]. In 2020, cranberry extract powder was the subject of GRN No. 873 that 
was submitted to the FDA. The cranberry extract powder was specified for intended use in beverages, beverage bases, readyto-drink coffee drinks at a level of $150 \mathrm{mg} / 8 \mathrm{oz}$ serving $(62.5 \mathrm{mg} /$ $100 \mathrm{~g}$ ), and processed fruits and fruit juices at a level of $300 \mathrm{mg} /$ $8 \mathrm{oz}$ serving $(125 \mathrm{mg} / 100 \mathrm{~g})$. The FDA had no questions and filed GRN No. 873 in May 2020 [40].

In July 2020, the FDA announced that it does not intend to object to the use of certain qualified health claims regarding the use of certain cranberry juice beverages and cranberry powder supplements and a reduced risk of recurrent UTI in healthy women [41]. In response to a petition to authorize a health claim regarding the relationship between the consumption of cranberry products and a reduced risk of recurrent UTI in healthy women, the FDA found limited and inconsistent credible scientific evidence to support an authorized claim. As a result, the petitioner agreed to have the petition evaluated as a qualified health claim petition. As described in the FDA's enforcement discretion letter, the agency does not intend to object to specified claims regarding consumption of cranberry juice beverages ( $8 \mathrm{oz}$.) containing at least $27 \%$ cranberry juice and cranberry DS containing at least $500 \mathrm{mg}$ of cranberry powder (100\% fruit) and a reduced risk of recurrent UTI in healthy women. The claims specified by FDA include qualifiers about the level of scientific evidence on the reduced risk of recurrent UTI in healthy women. For the qualified health claims, cranberry juice beverages have the qualifier "limited and inconsistent scientific evidence" and cranberry DS has the qualifier "limited scientific evidence". The qualified health claims do not include other conventional foods or food products made from or containing cranberries (e.g., dried cranberries or cranberry sauce).

Regulatory listings were found for the cranberry in other countries. In Canada, cranberry is recognized as a natural health product [42]. Health Canada's NHPID lists cranberry and dried cranberry juice as a Schedule 1 plant and Item 1 plant material under the natural health product regulations. For cranberry, the proper name listed in NHIPD is Vaccinium macrocarpon, and listed common names are American cranberry, cranberry, large American cranberry, and large cranberry [42]. Health Canada has monographs for cranberry and dried cranberry juice $[43,44]$. A total of 384 active licensed products containing cranberry were listed in Canada's LNHPD [45]. In 2017, the EFSA evaluated the safety of cranberry extract powder as a novel food ingredient under Regulation (EC) No 258/97 [46]. In March 2011, ANSES published an opinion on the potential effects of cranberry on community-acquired UTIs, which included a safety evaluation on cranberry juice and cranberry products [47]. In December 2020, the European Scientific Cooperative on Phytotherapy (ESCOP) published a monograph on cranberry [48]. A total of 97 approved single medicine products containing cranberry are listed in the Australian Register of Therapeutic Goods [49].

Data were searched to determine the daily intake levels of cranberry ingredients in DS on the market. Using the search term "cranberry" for product labels in the NIH Dietary Supplements Label Database (DSLD), as of September 11, 2019, up to 1817 products containing cranberry as an ingredient were listed [50]. Products that listed the amount of cranberry on the label had daily serving sizes that ranged from 2 to $2000 \mathrm{mg}$, and 1 product had a daily serving size as low as $50 \mu \mathrm{g}$ of cranberry. The products contained different preparations of cranberry such as cranberry powder, cranberry concentrate, or cranberry extract. The DS manufacturers' recommended daily intakes ranged from 4 to $5580 \mathrm{mg}$ of cranberry powder, 10 to $1350 \mathrm{mg}$ of cranberry extract, and 10 to $1500 \mathrm{mg}$ of cranberry concentrate. DS products containing cranberry had either single or multiple ingredients, and most are sold as either capsules or tablets.

In NDIN No. 918, the recommended daily intake of cranberry extract (containing 36\% PACs) as a DS is $120 \mathrm{mg}$ of cranberry extract powder or $1 \mathrm{~mL}$ of cranberry extract liquid, twice daily, providing a maximum daily intake of $240 \mathrm{mg}$ or $2 \mathrm{~mL}$, respectively (i.e., $1 \mathrm{~mL}$ of liquid contains $120 \mathrm{mg}$ of cranberry extract) [36]. The maximum intake of PACs from either cranberry extract powder or liquid is $86.4 \mathrm{mg} /$ day. Intake levels of cranberry extracts for use in foods have been described in GRN No. 873 [40] and the EFSA Journal [46]. In GRN No. 873, the mean and 90th percentile estimated daily intakes for cranberry extract powder (containing approximately 55\% PACs) from proposed food uses were described as 332 and $639 \mathrm{mg} /$ day, respectively. These intakes of extract provide 182.6 and $351.5 \mathrm{mg} /$ day of PACs, respectively [40]. The EFSA assessment of cranberry extract powder (containing 55$60 \%$ PACs) as a novel food reported that for the proposed uses in yogurts and beverages, the 95th percentile estimated daily intakes were $319 \mathrm{mg} /$ day in women and $366 \mathrm{mg} /$ day in men. These intake levels of cranberry extract provide 192 and $219 \mathrm{mg} /$ day PACs in women and men, respectively [46].

Health Canada monographs for cranberry and dried cranberry juice recommend intake levels of 10-30 g/day of fresh fruit, 90$950 \mathrm{~mL} /$ day of fruit juice, and 400-1200 mg/day of dried fruit juice when used as a source of antioxidants $[43,44]$. The American Botanical Council's Herbalgram Cranberry monograph reported intakes of 300 to $400 \mathrm{mg}$ of concentrated cranberry juice extract 2 to 3 times daily are recommended for the treatment and prevention of UTIs [51]. An intake of $300 \mathrm{~mL} /$ day of cranberry juice cocktail containing $36 \mathrm{mg} /$ day of PACs is recommended for the prevention of UTIs [24].

\section{Clinical Evidence of Safety}

The efficacy of cranberry preparations in the prevention of UTIs has been investigated in numerous clinical studies [20,24]. A 2012 CSR was conducted for cranberry clinical studies for UTI prevention [24]. The review assessed 24 clinical studies with a total of 4473 participants (updated from the last 2008 CSR) and included 6 cross-over studies, 11 parallel-group studies with 2 arms, 5 studies with 3 arms, and 2 with a factorial design. The studies evaluated cranberry juice cocktails or concentrates (30 to $1000 \mathrm{~mL}$ ) day) or cranberry tablets or capsules (400 to $2000 \mathrm{mg} /$ day). The CSR reported no significant difference between gastrointestinal (GI) adverse effects for groups treated with cranberry products compared to the placebo or no-treatment control groups (RR $0.83,95 \% \mathrm{Cl} 0.31$ to 2.27 ). Low compliance and high withdrawals reported in the clinical studies were attributed to the palatability or intolerance of the cranberry products, primarily for cranberry juice when taken over long periods [24]. Five studies reported no withdrawals, but the withdrawal rate reported in the other studies 
varied considerably, from 3 to $55 \%$. Two of the studies were conducted in pregnant women using high intake levels of cranberry juice (up to $1000 \mathrm{~mL} /$ day) and had withdrawals of $28 \%$ and $39 \%$ [24]. In one of the studies, the withdrawal of 73 out of 188 participants was mainly due to Gl upset including nausea, vomiting, diarrhea, and palatability issues. Therefore, the intake level of cranberry juice was reduced from $720 \mathrm{~mL}$ to $540 \mathrm{~mL}$ daily (240 mL taken 3 times daily, then reduced to 2 times daily) [52]. In the other study [53], the high withdrawal of 122 out of 380 participants was attributed to $\mathrm{Gl}$ upset in pregnant women when given $250 \mathrm{~mL}$ cranberry juice 4 times daily $(1000 \mathrm{~mL}$ daily) [53,54]. Another study, with a withdrawal rate of $55 \%$, was conducted in elderly participants $(n=38$; mean age $81 \mathrm{y}$ ) who were given $30 \mathrm{~mL}$ cranberry juice mixed with water for up to $4 \mathrm{wk}$. The concentration of juice and PAC content were not provided. The study was a cross-over design in which the control group was given the same volume of water [55]. Insufficient details were available to ascertain why this study had a high withdrawal rate for a low cranberry juice intake [24].

The CSR noted that many clinical studies were low quality and suggested that the use of encapsulated cranberry preparations may prevent the low compliance that was observed for cranberry juice [24]. However, most of the studies that used cranberry tablets or capsules did not report on the content of the active ingredients. Furthermore, PAC levels in the cranberry products were mostly unreported in the clinical studies [24]. AEs were not well reported across the clinical studies, and only 7 studies stated the number of AEs within each study arm. The AEs were mild, similarly distributed across treatment arms, and mainly GI-related adverse effects [24]. Another meta-analysis was comprised of 13 clinical trials examining the efficacy of cranberry products in preventing UTIs in 1616 mostly female patients (8 studies with juice or concentrate, 4 studies with tablets or capsules, and 1 study with both). While the authors did not discuss AEs or compliance rates in their analysis, they did note that the use of cranberry juice in clinical studies was associated with compliance issues [56].

A randomized clinical study published in 2012 evaluated the effects of consuming cranberry juice for 6 mo in women with a history of UTIs ( $n=176$ ) [57]. Women were given either $4 \mathrm{oz}$ of cranberry juice once daily ( $n=60), 8$ oz of cranberry juice once daily $(n=60)$, or a placebo juice $(n=56)$. The juice contained $27 \%$ cranberry juice and sucralose and was similar in composition to commercially available low-calorie cranberry juice. The PAC levels in the cranberry juice were not reported. Adverse effects were assessed at monthly visits, and no serious AEs were reported. Minor adverse effects included primarily $\mathrm{Gl}$ (constipation, heartburn, loose stool), vaginal (itching, dryness), and migraine symptoms. The proportions of women who reported minor adverse effects were 29 of 120 participants (24.2\%) in the cranberry juice groups and 7 of 56 participants $(12.5 \%)$ in the placebo group $(p=0.07)$. Three women in the cranberry treatment groups ( 1 woman given $4 \mathrm{oz}$ of cranberry juice and 2 women given 8 oz of cranberry juice) stopped taking the cranberry juice because of Gl symptoms thought to be related to the product. The authors noted that the tolerability of cranberry juice products has been problematic in clinical studies. However, the authors noted that participants in their study had higher adherence to daily intakes than individuals in previous studies. Therefore, the use of cranberry solids in products may be a more viable option for continuous daily intakes [57].

Other clinical studies not assessed in the CSR have evaluated cranberry extracts and their effects on UTI prevention. Three clinical studies published between 2015 and 2017 evaluated the efficacy of a standardized cranberry extract product in the following individuals with a history of recurrent UTIs: juveniles between 12 and $18 \mathrm{y}$ of age [58], adult females [59], and elderly men suffering from moderate prostatic hyperplasia [60]. The participants were given 1 daily capsule containing $120 \mathrm{mg}$ of cranberry extract, standardized to $36 \mathrm{mg}$ PACs, for up to 60 days. The authors reported that no AEs were observed in these studies, although the monitoring of AEs was not described, and no other clinical safety parameters were mentioned. All of the studies reported high compliance for the cranberry extract $(>91 \%$ in juveniles and $>95 \%$ in adult women and elderly men) [58-60].

One randomized placebo-controlled clinical study published in 2016 evaluated the efficacy of a standardized proanthocyanidin-A cranberry extract in patients with recurrent UTIs [61]. Patients were given one $60 \mathrm{mg}$ capsule of standardized proanthocyanidin A cranberry extract twice daily $(n=36)$ or a placebo $(n=36)$ for $12 \mathrm{wk}$. The concentration of proanthocyanidin A in the cranberry extract was not specified. The participants were assessed for side effects, AEs, and compliance, but no other clinical safety parameters were mentioned. The authors reported no AEs except for constipation in 1 subject in each group, and there were no withdrawals from the study. The authors concluded that the cranberry extract was well tolerated and shown to significantly lower the number of UTI episodes ( $<<0.001)$.

A double-blind, randomized, placebo-controlled efficacy study evaluated cranberry capsules on bacteriuria plus pyuria among older women in nursing homes [62]. The study was conducted from 2012 to 2015 in female nursing home residents $(n=185)$. Participants ( $n=92$ ) were given 2 cranberry capsules daily, with each capsule containing $36 \mathrm{mg}$ of PAC (i.e., $72 \mathrm{mg}$ PAC daily, equivalent to 20 ounces of cranberry juice) or a placebo $(n=93)$. Adherence was determined by the number of capsules administered to each subject (high adherence was defined as $\geq 80 \%$ ), and AEs were recorded and reviewed monthly. No other clinical safety parameters were described. During the study, 3830 AEs were reported, of which 116 were serious (83 hospitalizations and 33 deaths, all protocol-unrelated and anticipated) and 3714 were nonserious (14 protocol-related and anticipated). The authors reported that the nature and frequency of the 14 protocol-related and anticipated nonserious AEs-altered mental status, GI disturbance, oral cavity disturbance, skin and soft tissue events, and weight loss-were similar between the cranberry treatment and placebo groups.

One clinical study included healthy women who were given dried cranberry juice for 8 wk $(n=65)$ [63]. Women were given either placebo, 400 , or $1200 \mathrm{mg} /$ day of dried cranberry juice $(n=23,20$, and 22 , respectively). The dried cranberry juice contained $3 \%$ total polyphenolic content, $0.3 \%$ quercetin, and $0.44 \%$ anthocyanin pigments, along with $1-10 \%$ phenolic acids (w/w). The authors estimated that $1200 \mathrm{mg} /$ day of dried cranberry juice provided a daily intake of $35 \mathrm{mg}$ of total phenols, $7.8 \mathrm{mg}$ of antho- 
cyanins, and $14.4 \mathrm{mg}$ of PACs. Biochemical parameters (cholesterol, HDL cholesterol, LDL cholesterol, triacylglycerols, alanine transaminase, aspartate aminotransferase, gamma-glutamyltransferase, urea, creatinine, uric acid, and advanced oxidation protein products levels in serum) and hematological parameters (blood count, including a differential leukocyte count) were assessed. The authors reported that 57 out of 65 participants completed the study. Two women given the placebo withdrew, due to either respiratory illness (1) or personal reasons (1). Six women given $1200 \mathrm{mg} /$ day of dried cranberry juice withdrew, due to respiratory disease (2), excessive urination (1), stomach acidity (1), or personal reasons (1). However, the authors did not report the cause of the sixth withdrawal, or possibly only 5 women withdrew. No withdrawals were reported for the group given $400 \mathrm{mg} /$ day of dried cranberry juice. No adverse effects on biochemical and hematological parameters were reported for either treatment group, and values were within the normal physiological range. The authors concluded that an intake of $1200 \mathrm{mg} /$ day of dried cranberry juice was effective for preventing UTIs but did not discuss its safety. - Table 1 summarizes the key safety outcomes of each clinical study including a description of AEs and study withdrawals.

\section{Animal Toxicology, In Vitro Studies, and Pharmacokinetics}

An oral $L_{50}$ of $>5 \mathrm{~g} / \mathrm{kg}$ was established for a cranberry powder standardized to $1.5 \%$ PACs when administered to female Sprague Dawley rats in an acute study following Economic Cooperation and Development (OECD) guidelines [64]. Single oral doses up to $5600 \mathrm{mg} / \mathrm{kg}$ of cranberry ethanolic extract showed no lethality in CD-1 male mice [65]. No other details were reported for these acute studies.

A 14-wk study was conducted in male Wistar rats $(n=6$ per 3 experimental groups and a placebo group), where the experimental groups were each given a different commercial cranberry powder product in their diet at a concentration of $1500 \mathrm{mg}$ of cranberry product $/ \mathrm{kg}$ of feed $(1500 \mathrm{ppm})$ [66]. The treated rats were exposed to up to $0.60 \mathrm{mg} / \mathrm{kg} /$ day of PACs [46]. The cranberry products were well tolerated and did not affect hematology parameters, body weight, or food consumption. Plasma alkaline phosphatase was significantly decreased in one of the experimental groups $(p<0.05)$, but the authors did not mention if this change was adverse. No effects on organ weights, gross pathology, or histopathology were observed, and total cytochrome P450 levels in the liver were not affected by the treatment with the cranberry products [66]. The authors reported the daily dose of cranberry powder administered to rats that was 10 times higher than the intake level used in one clinical study in healthy women [63]. The clinical study used an intake level of $1200 \mathrm{mg} /$ day of dried cranberry juice and accordingly the human dose was approximately $17 \mathrm{mg} / \mathrm{kg} /$ day (1200 mg/day $\div 70 \mathrm{~kg}$ body weight). Therefore, the estimated dose of cranberry powder fed in rats was $170 \mathrm{mg} / \mathrm{kg} /$ day in which no toxicity was observed, indicating that commercial cranberry powder is safe in humans at an intake level that is 10 times lower than in rats.
One study evaluated cranberry extract powder's effect in dogs (schnauzers and Chihuahuas) with a history of recurrent UTIs [67]. The dogs ( $n=6$ per group) were given either $20 \mathrm{mg} / \mathrm{kg}$ cephalexin or cranberry extract powder ( $1 \mathrm{~g}$ for dogs $<25 \mathrm{~kg}$ and $2 \mathrm{~g}$ for dogs $\geq 25 \mathrm{~kg}$ ) for $6 \mathrm{mo}$. Monthly physical examinations, hematologic examinations, biochemical analysis, and urinalysis were performed. No adverse effects attributable to cranberry extract powder were reported by the authors, although no data were provided in the publication and the study was not designed to evaluate toxicity.

No reproductive or developmental toxicity studies were identified for cranberry ingredients. Three commercial cranberry products containing low phenolic concentrations were not genotoxic in peripheral lymphocytes of treated male Wistar rats when analyzed by the Comet assay [66]. No genotoxicity was observed in a micronucleus test conducted in CD-1 male mice orally administered $800 \mathrm{mg} / \mathrm{kg} /$ day of cranberry ethanolic extract for $1 \mathrm{wk}$ [65]. No Ames or in vitro micronucleus tests and no chronic or carcinogenicity studies were available for cranberry ingredients. $>$ Table $\mathbf{2}$ summarizes the key safety outcomes of each preclinical study including a description of any adverse effects.

Limited pharmacokinetic studies were available for cranberry ingredients. Male Wistar rats administered 3 commercial cranberry powder products at $1500 \mathrm{ppm}$ in the diet for $14 \mathrm{wk}$ showed significantly higher concentrations of phenolic acids in their plasma, urine, feces, and liver compared to control rats [66]. Levels of anthocyanins in plasma, feces, urine, and liver were under the limit of quantification $(<10 \mu \mathrm{g} / \mathrm{mL})$, which may be explained by their conversion into hippuric acid. Hippuric acid was significantly elevated in the urine of treated rats, and it appears to be the main metabolite of phenolic acids, benzoic acid, flavonoids, anthocyanins, and probably PACs. The urine concentration of hippuric acid corresponded well with intakes of phenolics [66].

The absorption of PACs is low, and only PACs with a low degree of polymerization (i.e., dimers) can be absorbed. Oligomeric and polymeric PACs are proposed to be transported to the large intestine and broken down into simple phenolic acids by microbiota and are subsequently absorbed. PAC polymers could be degraded into monomers under the acidic conditions of the stomach based on in vitro studies, although this may not occur readily in humans [46].

\section{AEs Associated with Cranberry}

In the clinical studies reviewed herein, no serious AEs were reported for cranberry. The most common AEs observed for cranberry involved the GI tract. GI symptoms such as diarrhea may result from high intakes (more than 3 to $4 \mathrm{~L}$ daily) of cranberry juice $[51,56]$. Gl distress, including diarrhea, was reported in infants and children consuming more than $3 \mathrm{~L}$ daily of cranberry juice [26]. The 2011 published opinion by ANSES on the potential effects of cranberry on community-acquired UTIs included a safety evaluation on cranberry juice and cranberry products, and it noted that side effects were predominantly Gl-related (gastroesophageal reflux, nausea, and digestive disorders) and mostly observed for large intakes of cranberry juice or beverage over prolonged periods. ANSES concluded that "there is no safety concern 

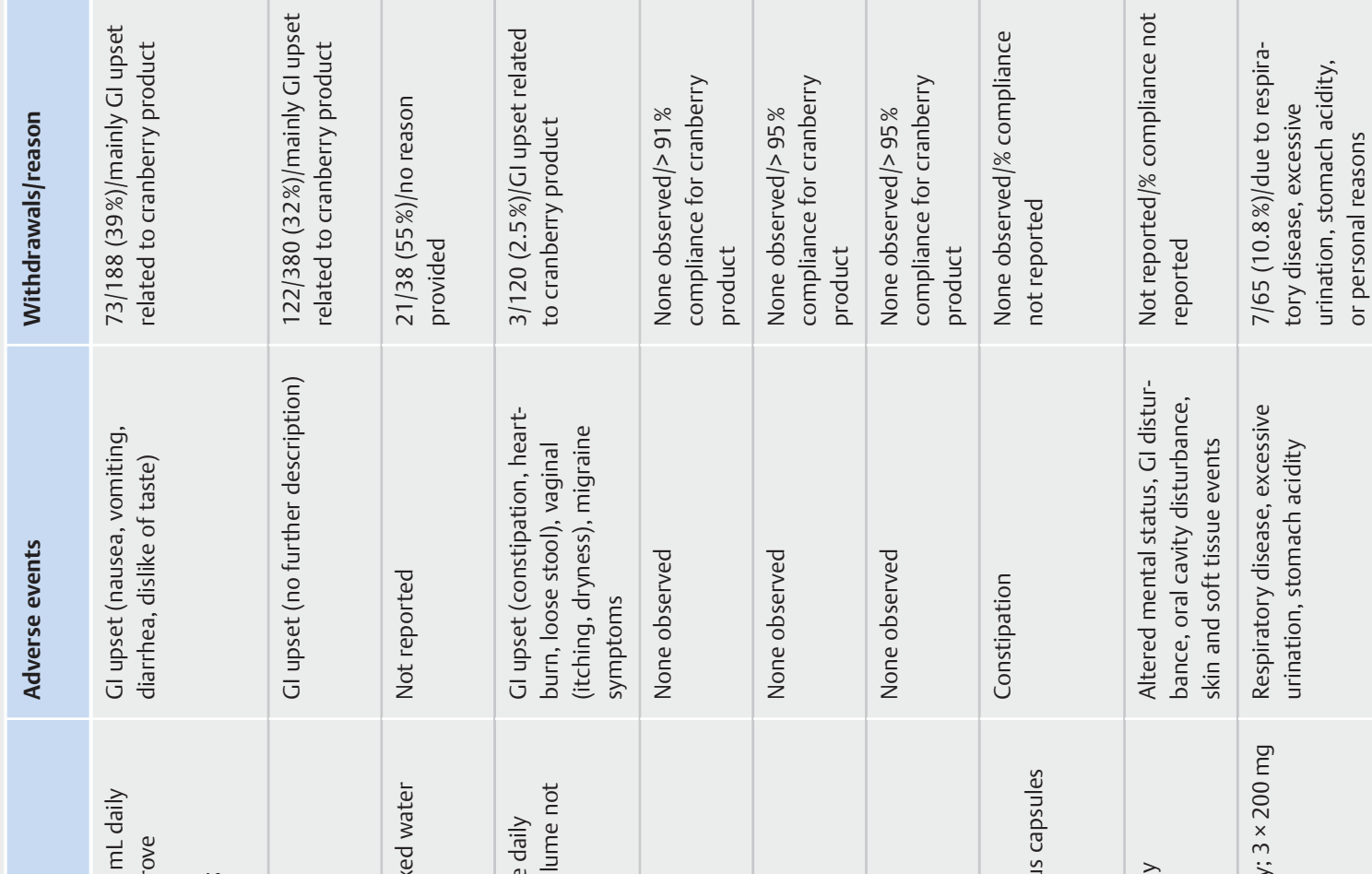

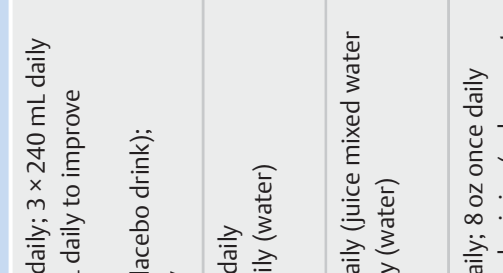

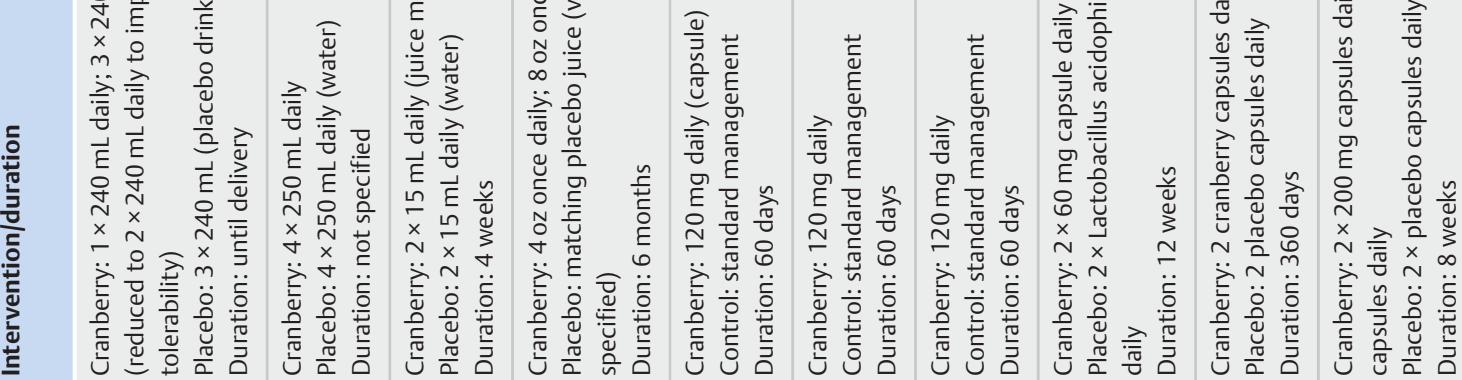
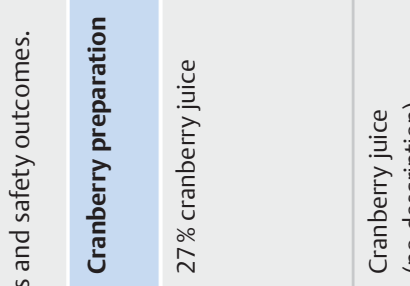

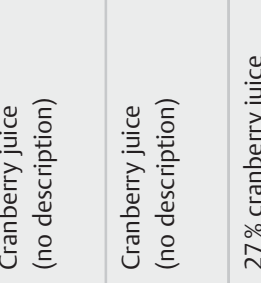
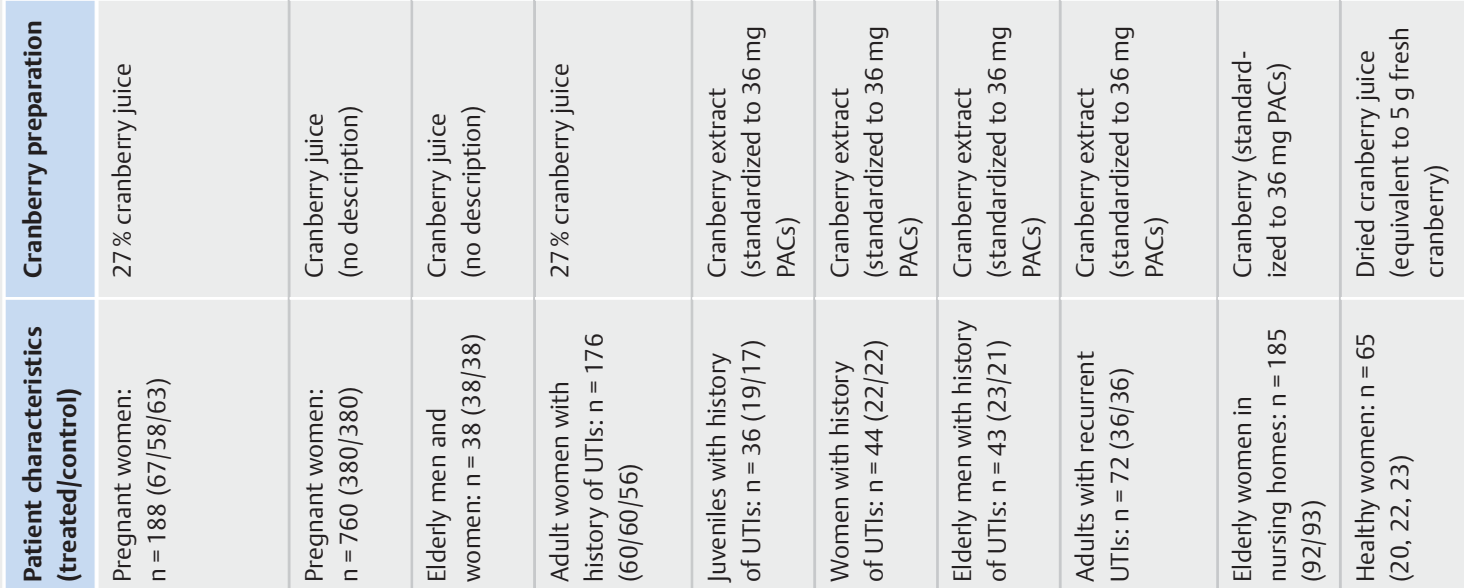

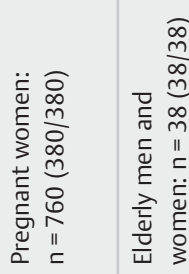

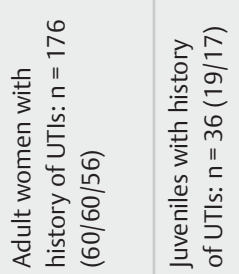

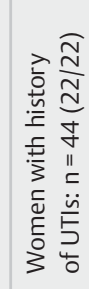

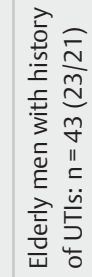

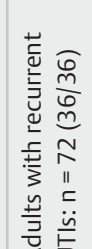

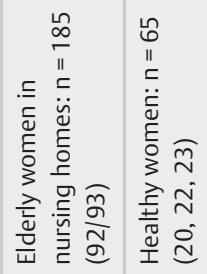

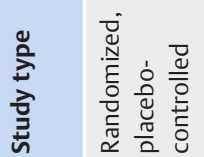

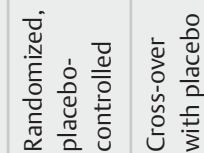

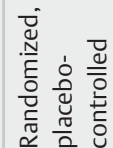

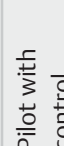

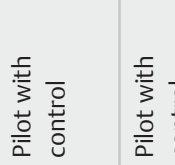

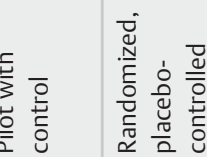

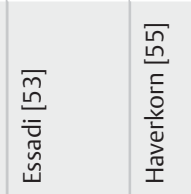

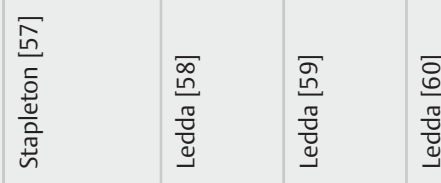

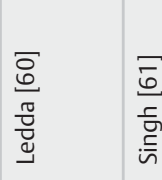

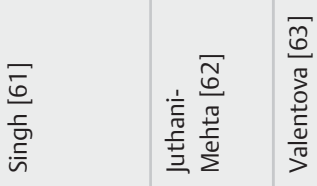




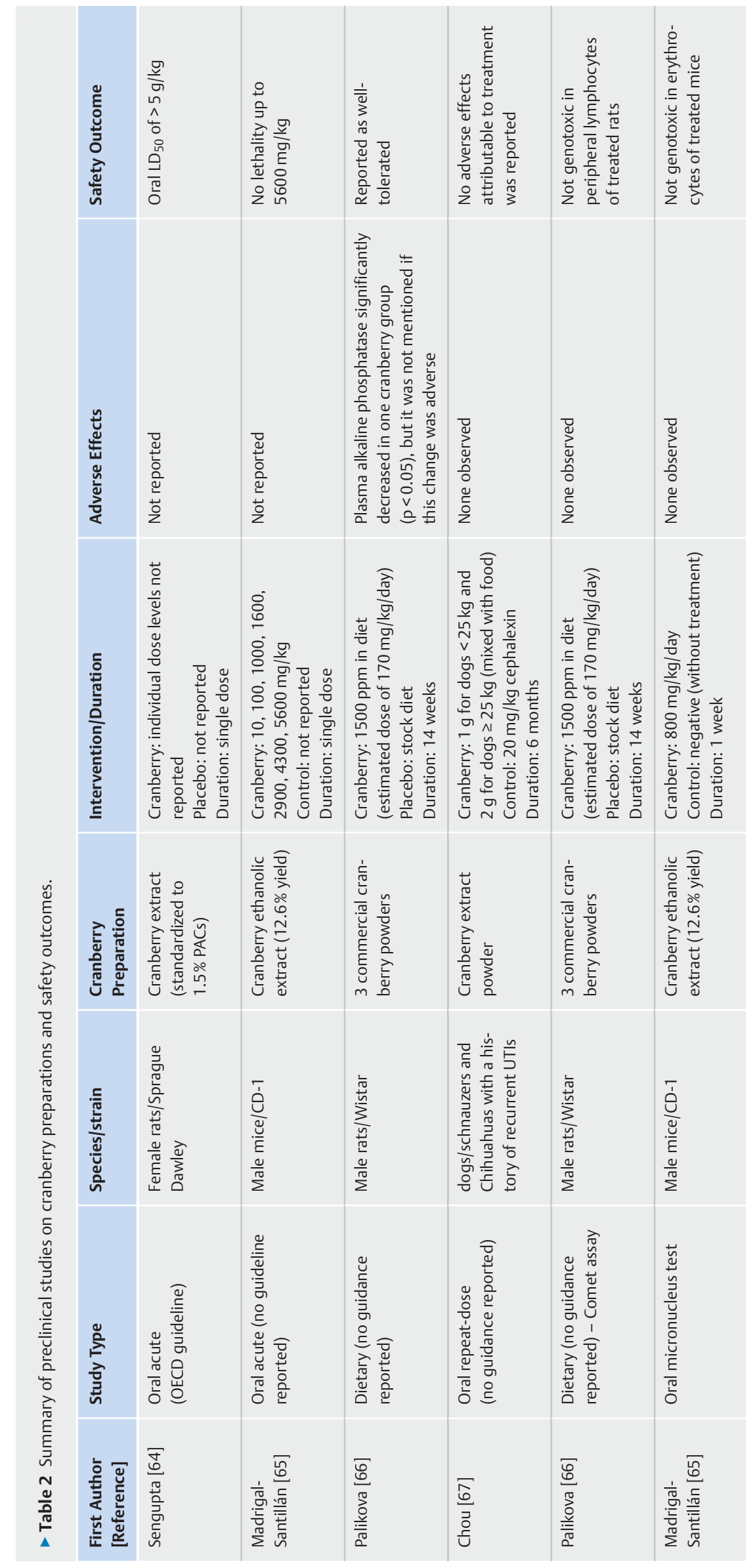


related to the consumption of cranberry by the general population. Adverse effects are mainly digestive and usually occur after high consumption of cranberry over the long term, particularly as a beverage" [47].

The AHPA Botanical Safety Handbook classifies cranberry as Safety Class I (i.e., an herb that can be safely consumed when used appropriately) [17]. One published review assessing cranberry in the prevention of UTIs reported that besides issues with palatability, there are no safety concerns $[17,68]$. Nevertheless, some potentially serious AEs have been reported in case reports describing the use of cranberry. These include kidney stone formation and herbal-drug interactions, specifically with the anticoagulant drug warfarin. The case reports and the available studies associated with cranberry are described below.

A search using the term "cranberry" was conducted of the publicly available FDA CAERS database. The results included 292 AE reports (AERs) [69]. The majority of the AERs were related to cranberry juice products; however, AERs were also related to other cranberry preparations, including tablets, caplets, soft gels, pills, and extracts. Some AERs did not include the specific type of cranberry product. Causality assignment was not possible, in part, because the majority of these AERs involved multi-ingredient products and/or the concomitant intake of other supplement products.

The Canada Vigilance Program database was searched using the following keywords: "cranberry", "cranberry extract”, "cranberry juice powder", "dried cranberry extract”, and "dried cranberry juice". The search yielded a total of 43 AERs related to cranberry products [70]. Two AERs for cranberry juice products described decreased prothrombin levels or a prolonged prothrombin time. Both involved the use of the drug warfarin/Coumadin. Additionally, both AERs involved the simultaneous intake of other medications. Another AER for cranberry tablet described an increased INR but involved the simultaneous intake of a prescription blood thinner/anticoagulant and other herbal products. The AERs included varied symptoms with no specific target organ system, and they involved multi-ingredient products and/or the concomitant intake of multiple health products or medications. Due to these factors, a causality assignment was not possible.

A total of 28 AERs associated with cranberry were listed in the Australian TGA DAEN [71]. Of the 4 AERs involving the use of a cranberry product and the medication warfarin, 3 described an increase in the INR and 1 included an abnormal coagulation test. Three of the AERs involved the concomitant intake of other supplement products or medicines. The AER that involved the intake of only 1 cranberry product with warfarin did not include the cranberry product ingredients. However, a follow-up internet search of commercially available products showed it contained dried cranberry juice (equivalent to $10 \mathrm{~g}$ of fresh fruit) and $100 \mathrm{mg}$ of vitamin C (ascorbic acid). Because this AER was reported in 2004, it is uncertain whether the product formulation contained the same content or ingredients that are currently available. Overall, a causality assignment was not possible, in part, because the AERs involved multi-ingredient products and/or the concomitant intake of other supplement products or medicines.
No AERs were listed for cranberry in the following databases: British MHRA Yellow Card database [72], the EudraVigilance European database [73], and New Zealand's MedSafe [74].

\section{Kidney Stone Formation and Cranberry}

Human clinical studies have reported contradictory data about cranberry and its role in kidney stone formation [17]. Some studies indicated that individuals with a history of developing uric acid or calcium oxalate stones are at risk when consuming cranberry products [75]. In contrast, other studies have reported that consumption of large amounts of cranberry may reduce kidney stone formation or urinary ionized calcium associated with stone formation $[51,76,77]$. One case report of kidney stone formation associated with the intake of a DS containing cranberry was identified. A 47-year-old man with a history of kidney stones presented with right renal colic and hematuria and a creatinine level of $2.1 \mathrm{mg} / \mathrm{dL}$. Abdominal films revealed multiple kidney stones and distal ureteral and mid ureteral stones. The patient had taken cranberry concentrate tablets twice daily for the previous 6 mo and had no kidney stones 1 year before the AE. The kidney stones in the patient were determined to consist of calcium oxalate. It was not reported if the patient was taking other supplements or medications at the time. The authors did not report the level of cranberry concentrate in the tablets taken by the patient. However, they mentioned that several brands of cranberry concentrate tablets are commercially available and the product label for one commercially available $450 \mathrm{mg}$ tablet of cranberry concentrate (equivalent to $2880 \mathrm{~mL}$ of cranberry concentrate juice) includes the recommendation to take the tablet twice daily [75].

Based on this case report described above, a clinical study was conducted to further investigate the link between kidney stone formation and cranberry concentrate tablets. The study reported a significant increase in urinary oxalate levels in healthy participants given cranberry concentrate tablets for $1 \mathrm{wk}(n=5)$ [75], prompting caution that individuals with existing nephrolithiasis might be at increased risk of kidney stone formation when consuming large amounts of cranberry $[26,78]$. The study also reported a significant increase in urinary calcium, phosphate, and sodium, along with magnesium and potassium, which are both inhibitors of stone formation. The authors proposed that the oxalate content in cranberry could cause kidney stone formation; however, the authors did not measure oxalate levels in the cranberry tablets. The authors noted there is one report that a $30 \mathrm{~mL}$ volume of cranberry juice contains approximately $1.89 \mathrm{mg}$ of oxalate. Although the oxalate content in the tablets was not reported, the authors estimated that if the oxalate content was proportional to the volume of cranberry juice in the tablets, then the twice-daily dosing with cranberry tablets containing $450 \mathrm{mg}$ of cranberry concentrate would contain approximately $363 \mathrm{mg}$ of oxalate per day [75]. Notably, the clinical study was criticized for not measuring the content of oxalate in the cranberry concentrate tablets and for not assessing dietary intakes of vitamin $\mathrm{C}$ or calcium in the participants, both of which can contribute to urinary oxalates [79].

Other studies have reported contradictory findings regarding the role of cranberry in kidney stone formation, and the risk may 
depend on the different types of stone formation (i.e., calcium oxalate versus apatite, brushite, and struvite stone formation). A systematic review and meta-analysis reported that insufficient data were available to link cranberry juice to the risk of kidney stones, although some studies have reported that various juices, including cranberry juice, are associated with reducing the risk of kidney stones [80]. One clinical study reported that $500 \mathrm{~mL}$ of cranberry juice given to healthy men for 2 wk had shown favorable effects on risk factors for stone formation $(n=20)$, which included a decrease in oxalate and phosphate excretion, an increase in citrate excretion, and a decrease in relative supersaturation of calcium oxalate [76]. The authors noted that participants given cranberry juice had significantly higher dietary intakes of oxalate and ascorbic acid ( $p=0.0184$ and $<0.001$, respectively), which were attributed to the content of oxalate and ascorbic acid measured in the cranberry juice $(86 \mathrm{mg} / \mathrm{mL}$ and $300 \mathrm{mg} / \mathrm{L}$, respectively) compared to control participants given water. The authors concluded that cranberry juice shows antilithogenic properties [76]; however, the intake of oxalate from the cranberry juice $(43 \mathrm{mg} /$ day) used in this study was an order of magnitude lower than the estimated intake of oxalate (363 mg/day) in the clinical study [75] that evaluated cranberry concentrate tablets.

A 7-day clinical study evaluated the effects of consuming $1 \mathrm{~L}$ of cranberry juice daily in healthy individuals and those with a history of forming calcium oxalate stones ( $n=12$ per group) [81]. Cranberry juice significantly increased urinary calcium and urinary oxalate levels, thereby increasing urinary saturation of calcium oxalate by $18 \%$ across treatment groups. However, urinary citrate was unchanged; urinary magnesium increased slightly; and urinary ammonium, titratable acidity, and net acid excretion increased. Urinary and serum uric acid also decreased, which the authors mentioned could offset the propensity of uric acid crystallization associated with a lower urinary $\mathrm{pH}$. The authors concluded that cranberry juice exerts a mixed impact on the crystallization of kidney-stone-forming salts: while crystallization of calcium oxalate was enhanced, brushite and monosodium urate saturation were reduced. Overall, cranberry juice may not substantially affect kidney stone formation.

In another study, healthy male participants given $330 \mathrm{~mL}$ of cranberry juice daily for 5 days had decreased urinary $\mathrm{pH}$ and increased excretion of oxalic acid and relative supersaturation of uric acid $(n=12)$. Excretions of citric acid, calcium, magnesium, and uric acid were not significantly altered, and the relative supersaturation for struvite and brushite was decreased but did not reach statistical significance. The increased oxalic acid excretion was proposed to be caused by the oxalic acid content in cranberry juice $(167 \mu \mathrm{mol} / \mathrm{L}$ oxalic acid). The authors concluded that since cranberry juice lowers the $\mathrm{pH}$ of urine, it could be useful for the treatment of apatite, brushite, and struvite stones as well as urinary tract infections; however, more research is needed in patients with a history of kidney stones [82].

Patients with a history of struvite stones who consumed 2 pints of cranberry juice per day for 9 y had no recurrence of stones $(60 \%$ of patients), no increase of stone size (32\%), and no new stones or an increase in stone size (6\%); however, the study did not include a control group [17, 83].
Health Canada monographs have the following caution statement for the intake of cranberry in individuals with a history of kidney stones: "Consult a health care practitioner/health care provider/health care professional/doctor/physician before use if you have a history of kidney stones" [43,44]. The 2011 ANSES opinion concluded that "...given the data showing increased urinary excretion of calcium oxalate, long-term consumption of cranberry in individuals prone to oxalate kidney stones is not recommended" [47]. The ESCOP monograph on cranberry recommends that patients with a history of calcium oxalate stone formation should seek medical advice before taking cranberry [48].

No AERs suggesting kidney stone formation associated with cranberry products were found in searches of publicly available databases including the FDA CAERS [69] and the Canada Vigilance Program database [70].

\section{Potential Drug Interactions with Cranberry}

Cases of cranberry interactions with warfarin were found in the literature search for cranberry and drug interactions. Available clinical data and case reports suggest that high intakes of cranberry juice (approximately 1-2 L) or cranberry extracts (3000 mg/day) could potentially interfere with warfarin. However, moderate intakes of cranberry juice ( 240 to $480 \mathrm{~mL}$ ) in clinical studies did not exhibit interactions with warfarin. Cases of elevated INR have been reported in patients taking cranberry and warfarin [84-86]. One review evaluated 6 published case reports and 9 unpublished reports received by the United Kingdom Committee of the Safety of Medicine. Of the 15 reports on cranberry juice-warfarin interactions, only 2 had a "probable" interaction. The remaining reports had a "possible" interaction score. In these cases, many of the patients had a serious illness, were taking concomitant medications, had dietary changes, and/or were consuming excessive amounts of cranberry juice. The 2 "probable" cases were questionable since one case involved a patient who was taking antibiotics and consuming high volumes of cranberry juice ( $2 \mathrm{~L}$ daily) and the other case involved a patient who had stopped consuming cranberry juice 2 days before showing an elevated INR [86].

No clinically relevant interactions were found in a review of 7 randomized clinical studies that evaluated interactions between cranberry juice and warfarin or surrogate drugs metabolized by the same isoenzymes as warfarin [86]. Other published reviews reported that the available evidence does not indicate clinically relevant interactions between cranberry juice and warfarin [85, 86]. One clinical study reported that $250 \mathrm{~mL}$ of cranberry juice given to male patients on warfarin therapy did not affect prothrombin time or INR $(n=7)$ [18]. Another study reported no statistical difference between mean prothrombin and baseline in men taking stable doses of warfarin and consuming $240 \mathrm{~mL}$ cranberry juice twice daily for 7 days $(n=10)$ [87]. Clinical trials did not identify an interaction between cranberry juice and cytochrome P450 (CYP) 2C9 and 3A4 enzymes, both of which are required in warfarin metabolism [85]. One clinical study reported that an intake of $8 \mathrm{oz}(240 \mathrm{~mL})$ of cranberry juice did not affect CYP2C9 activity in 14 healthy participants given the analgesic drug flurbiprofen, which is a substrate for CYP2C9 [88]. A clinical study of 12 healthy male volunteers found that consuming $240 \mathrm{~mL}$ of cran- 
berry juice had no effect on the metabolism of cyclosporine, which is a substrate for CYP3A4 [89].

Notably, these clinical studies evaluated moderate intakes of cranberry juice (approximately 8 to $16 \mathrm{oz}$ or 240 to $480 \mathrm{~mL}$ ), whereas some of the case reports describing warfarin interactions involved higher intakes. Other reviews of the available data and case reports suggest that intakes of large volumes of cranberry juice (approximately $1-2 \mathrm{~L}$ daily) may affect warfarin therapy. In contrast, smaller amounts of cranberry juice are not expected to cause drug interactions $[84,90]$. Cranberry juice concentrates in supplements may affect warfarin when taken for extended periods (more than 3-4wk) [90]. One clinical study evaluated the interaction potential between warfarin $(25 \mathrm{mg} /$ day $)$ and $1000 \mathrm{mg}$ of concentrated cranberry extract tablets taken 3 times daily $(3000 \mathrm{mg} /$ day) in healthy participants $(n=12)$. The authors reported that the cranberry extract had increased the area under the INR-time curve by approximately $30 \%$ when it was administered with warfarin compared to warfarin treatment alone, a statistically and clinically significant difference. The pharmacokinetics and plasma protein binding of $S$ - or $R$-warfarin were not altered by cranberry extract. The authors concluded that cranberry extract can affect warfarin pharmacodynamics with the potential to increase its effects, but without altering its pharmacokinetics [91]. However, the equivalence between cranberry juice and cranberry extracts has not been well established. The study used an equivalent of $57 \mathrm{~g}$ (4 tablespoons) of dry cranberry daily, but data comparing the equivalence between dry cranberry and cranberry juice are not available [86].

Regulatory bodies in other countries have provided cautions for cranberry concerning the potential for drug interactions. Health Canada monographs for cranberry and dried cranberry juice include the following caution statement for the intake of cranberry in individuals taking blood thinners: "Consult a health care practitioner/health care provider/health care professional/ doctor/physician prior to use if you are taking blood thinners" $[43,44]$. The ANSES opinion noted that published reviews and studies reported no risk of warfarin interactions with moderate cranberry juice intakes. However, ANSES noted that risk at higher intake levels (>600 mL/day) cannot be overlooked [47]. The ESCOP monograph on cranberry has also noted that interaction between cranberry juice and warfarin is unlikely, especially for moderate intakes of cranberry [48].

Published reviews on cranberry note that no significant drug interactions with cranberry have been reported [78] and that the potential for clinically important interactions is low [92]. The AHPA Botanical Safety Handbook classifies cranberry as Interaction Class A (i.e., an herb for which no clinically relevant interactions are expected) [17]. Blood thinner drug product inserts specifically warn about interaction risks associated with other drugs and botanical products. The prescribing information for Coumadin (warfarin sodium) advises patients not to take botanical (herbal) supplement products except on the advice of a health care provider. Cranberry was not explicitly listed in the available prescribing information for Coumadin [93].

A total of 7 AERs reported to Health Canada [70] and the Australian TGA DAEN [71] involved changes in INR or coagulation parameters in consumers ingesting cranberry juice or products containing cranberry-derived ingredients while taking prescription blood thinners. However, these AERs involved the use of multi-ingredient products and/or the concomitant intake of other products or medications, and causality could not be determined.

\section{Conclusion}

The purpose of this review was to determine if any relevant safety concerns would prevent the admission of cranberry to the USP monograph development process. The USP DSAE JS3 considered all the available data and concluded that there was no serious risk to human health associated with the use of DSs containing cranberry when used at the recommended intake levels in products currently on the market. Clinical data indicate no serious adverse effects were associated with the ingestion of cranberry juice or juice concentrates and other cranberry preparations such as tablets or capsules. The most common AEs were Gl complaints. Low compliance and high withdrawal rates attributed to palatability or GI complaints were mainly associated with cranberry juice. The use of encapsulated cranberry preparations is suggested to offset the low compliance that is observed for cranberry juice [24]. The small number of reported AEs relative to the widespread consumption of cranberry juice indicates a low risk of adverse effects for cranberry [17].

This review found that drug-herbal interactions with warfarin and kidney stone formation were identified as potential risks to human health, and these safety concerns were assessed by the USP DSAE JS3. Available data indicate no risk of warfarin interactions with moderate intakes of cranberry juice, although higher intakes cannot be overlooked [47]. Moderate intakes of cranberry juice have not exhibited interactions with warfarin, but ingestion of large amounts of cranberry juice (approximately 1-2 L) or cranberry extract $(3000 \mathrm{mg} /$ day) could potentially interfere with warfarin [84-86, 91]. DS products have recommended intakes of less than $1350 \mathrm{mg} /$ day of cranberry extract, which suggests that cranberry extracts less than this amount are not likely to cause adverse interactions. No evidence of clinically relevant interactions between cranberry juice and warfarin has been reported $[85,86]$.

Human studies have shown contradictory data regarding the role of cranberry in kidney stone formation [17]. Some clinical studies have indicated that individuals with a history of developing uric acid or calcium oxalate stones are at risk when consuming cranberry products [75], while other studies have reported that consumption of large amounts of cranberry may reduce kidney stone formation or reduce urinary ionized calcium associated with stone formation $[51,76,77]$. There is insufficient data to suggest kidney stone formation is associated with intakes of cranberry [80].

Based on the safety review conducted, the following cranberry ingredient monographs were admitted to the USP monograph development process: Cranberry Fruit Juice, Cranberry Fruit Juice Concentrate, Cranberry Fruit Juice Dry Extract, and Cranberry Fruit Dry Juice. Limited safety information is available on cranberry use during pregnancy or lactation, but traditional consumption of cranberry suggests no adverse effects [17]. However, because of limited safety data on their use by pregnant or breastfeeding women, cranberry DS products claiming compliance with USP 
standards will be expected to comply with the USP-NF General Chapter $<7>$ Labeling, which states that the label of an herb or other botanical intended for use as a DS shall bear the following statement: "If you are pregnant or nursing a baby, seek the advice of a health professional before using this product". Based on the available data, the USP DSAE JS3 concluded that cautionary labeling statements regarding the use of cranberry ingredients for individuals on blood thinners or those at risk for kidney stone formation are not necessary for quality standards pertaining to cranberry ingredients in DS products.

Recommendations can be made for further research to clarify some of the uncertainties associated with cranberry based on the literature that was assessed in this review. More studies are required to further clarify the role between cranberry and kidney stone formation. Because clinical studies have evaluated variable cranberry preparations with often limited to no detail on their chemical profiles, studies with better experimental designs are needed along with a clear identification of the bioactive constituents present in the cranberry preparations being studied. Preclinical studies on the safety of cranberry and its constituents were found to be generally lacking. Further in vitro and in vivo toxicology studies are recommended to provide more safety information on cranberry preparations and their constituents.

\section{Contributors' Statement}

Data collection: E. Madden, C. McLachlan, A. I. Calderon. Analysis and interpretation of the data: E. Madden, C. McLachlan, A. I. Calderon. Drafting the manuscript: E. Madden, C. McLachlan. Critical revision of the manuscript: E. Madden, H. Oketch-Rabah, A. I. Calderon.

\section{Acknowledgements}

The authors wish to thank members of the 2015-2020 USP Dietary Supplements Admission Evaluation Joint Standard Setting Subcommittee for valuable discussions of the review, as well as the following colleagues at USP: Virginia (Kit) Goldman and Maria J. Monagas for critically reviewing the manuscript, and Nick Healy for copyediting the manuscript.

\section{Conflict of Interest}

The authors declare that they have no conflict of interest.

\section{References}

[1] Janick J. The Origins of Fruits, Fruit Growing, and Fruit Breeding. In: Janick J, ed. Plant Breeding Reviews. Hoboken, New Jersey: John Wiley \& Sons, Inc.; 2005: 255-321

[2] Neto CC, Vinson JA. Chapter 6. Cranberry. 2 ed. Boca Raton, FL: CRC Press/Taylor \& Francis; 2011

[3] Stang E. The North American cranberry industry. Acta Hortic 1993; 346: 284-298

[4] Raz R, Chazan B, Dan M. Cranberry juice and urinary tract infection. Clin Infect Dis 2004; 38: 1413-1419

[5] Bodel PT, Cotran R, Kass EH. Cranberry juice and the antibacterial action of hippuric acid. J Lab Clin Med 1959; 54: 881-888
[6] Howell AB, Reed JD, Krueger CG, Winterbottom R, Cunningham DG, Leahy M. A-type cranberry proanthocyanidins and uropathogenic bacterial anti-adhesion activity. Phytochemistry 2005; 66: 2281-2291

[7] Foo LY, Lu Y, Howell AB, Vorsa N. A-Type proanthocyanidin trimers from cranberry that inhibit adherence of uropathogenic P-fimbriated Escherichia coli. J Nat Prod 2000; 63: 1225-1228

[8] Gupta K, Chou MY, Howell A, Wobbe C, Grady R, Stapleton AE. Cranberry products inhibit adherence of P-fimbriated Escherichia coli to primary cultured bladder and vaginal epithelial cells. J Urol 2007; 177: 23572360

[9] Howell AB, Botto H, Combescure C, Blanc-Potard AB, Gausa L, Matsumoto T, Tenke P, Sotto A, Lavigne JP. Dosage effect on uropathogenic Escherichia coli anti-adhesion activity in urine following consumption of cranberry powder standardized for proanthocyanidin content: a multicentric randomized double blind study. BMC Infect Dis 2010; 10: 94

[10] Zhao S, Liu H, Gu L. American cranberries and health benefits-an evolving story of 25 years. J Sci Food Agric 2018; 100: 5111-5116

[11] Neto CC. Cranberry and its phytochemicals: a review of in vitro anticancer studies. J Nutr 2007; 137: 186S-1935

[12] Philip E. Marucci Center for Blueberry and Cranberry Research. New Jersey Agricultural Experiment Station (NJAES) of Rutgers University. Accessed March 25, 2020 at: https://pemaruccicenter.rutgers.edu/ plant-products-health-benefits/

[13] Smith T, May G, Eckl V, Reynolds C. US sales of herbal supplements increase by $8.6 \%$ in 2019. Market Report. HerbalGram, Issue 127. Accessed March 22, 2021 at: http://herbalgram.org/media/15608/ hg127-hmr.pdf

[14] FDA. Draft guidance for industry: new dietary ingredient notifications and related issues. Accessed March 22, 2021 at: https://www.fda.gov/ regulatory-information/search-fda-guidance-documents/draftguidance-industry-new-dietary-ingredient-notifications-and-relatedissues

[15] Oketch-Rabah HA, Roe AL, Muldoon-Jacobs K, Giancaspro GI. Challenges and opportunities for improving the safety assessment of botanical dietary supplements: A United States Pharmacopeia perspective. Clin Pharmacol Ther 2018; 104: 426-429

[16] United States Pharmacopeia. Guideline for the Admission of Dietary Supplement Ingredients to the USP-NF Monograph Development Process. Accessed August 7, 2020 at: https://www.usp.org/sites/default/ files/usp/document/get-involved/submission-guidelines/guideline-forthe-admission-of-dietary-supplement-ingredients.pdf

[17] Gardner Z, McGuffin M. American Herbal Products Association's botanical Safety Handbook. Boca Raton, FL: CRC Press; 2013

[18] Li Z, Seeram NP, Carpenter CL, Thames G, Minutti C, Bowerman S. Cranberry does not affect prothrombin time in male subjects on warfarin. J Am Diet Assoc 2006; 106: 2057-2061

[19] Blumberg JB, Camesano TA, Cassidy A, Kris-Etherton P, Howell A, Manach C, Ostertag LM, Sies H, Skulas-Ray A, Vita JA. Cranberries and their bioactive constituents in human health. Adv Nutr 2013; 4: 618632

[20] Guay DR. Cranberry and urinary tract infections. Drugs 2009; 69: 775807

[21] Aron PM, Kennedy JA. Flavan-3-ols: nature, occurrence and biological activity. Mol Nutr Food Res 2008; 52: 79-104

[22] Gu L, Kelm MA, Hammerstone JF, Beecher G, Holden J, Haytowitz D, Gebhardt S, Prior RL. Concentrations of proanthocyanidins in common foods and estimations of normal consumption. J Nutr 2004; 134: 613617

[23] Prior RL, Fan E, Ji H, Howell A, Nio C, Payne M], Reed J. Multi-laboratory validation of a standard method for quantifying proanthocyanidins in cranberry powders. J Sci Food Agric 2010; 90: 1473-1478 
[24] Jepson RG, Williams G, Craig JC. Cranberries for preventing urinary tract infections. Cochrane Database Syst Rev 2012; (10): Cd001321

[25] Narwojsz A, Borowska E]. Cranberry and strawberry juices-influence of method production on antioxidants content and antioxidative capacity. Pol J Nat Sci 2010; 25: 209-214

[26] Dugoua J], Seely D, Perri D, Mills E, Koren G. Safety and efficacy of cranberry (Vaccinium macrocarpon) during pregnancy and lactation. J Popul Ther Clin Pharmacol 2008; 15: e80-e86

[27] Caillet S, Lorenzo G, Côté J, Sylvain JF, Lacroix M. Free radical-scavenging properties and antioxidant activity of fractions from cranberry products. Food Nutr Sci 2012; 3: 337-347

[28] White BL, Howard LR, Prior RL. Proximate and polyphenolic characterization of cranberry pomace. J Agric Food Chem 2010; 58: 4030-4036

[29] White BL, Howard LR, Prior RL. Polyphenolic composition and antioxidant capacity of extruded cranberry pomace. J Agric Food Chem 2010; 58: 4037-4042

[30] Roopchand DE, Krueger CG, Moskal K, Fridlender B, Lila MA, Raskin I. Food-compatible method for the efficient extraction and stabilization of cranberry pomace polyphenols. Food Chem 2013; 141: 3664-3669

[31] Brendler T, Gafner S. Adulteration of cranberry (Vaccinium macrocarpon). Cranberry Adulteration Bulletin released by Botanical Adulterants Program. American Botanical Council [Epub December 18, 2017]. Accessed September 12, 2019 at: http://cms.herbalgram.org/press/2017/ CranberryAdulterationBulletinReleasedbyBotanicalAdulterantsProgram. html?ts=1567792646\&signature=800f7af04c2bb548019caf343c48b 598

[32] Heitmann K, Nordeng $\mathrm{H}$, Holst L. Pregnancy outcome after use of cranberry in pregnancy-the Norwegian mother and child cohort study. BMC Complement Altern Med 2013; 13: 345

[33] United Natural Products Alliance (UNPA). Old Dietary Ingredient List. Dated 1999. Accessed September 12, 2019 at: https://web.archive.org/ web/20170510202500/https://www.fda.gov/ohrms/dockets/dockets/ 04n0454/04n-0454-c000014-01-vol5.pdf

[34] McGuffin M, Kartesz ], Leung A, Tucker A. Herbs of Commerce. 2nd ed. Austin, TX: American Herbal Products Association (AHPA); 2000

[35] American Herbal Products Association (AHPA) New Dietary Ingredient (NDI) Database. NDIN No. 902. Oximacro. Submitted by Biosfered S.r.l. on December 11, 2015. Accessed September 11, 2019 at: http://ndi. ahpa.org/Default.aspx?TabID=62\&SearchTerm=RPT902

[36] American Herbal Products Association (AHPA) New Dietary Ingredient (NDI) Database. NDIN No. 918. Oximacro. Submitted by Biosfered S.r.I. on April 12, 2016. Accessed September 11, 2019 at: http://ndi.ahpa. org/Default.aspx?TabID=62\&SearchTerm=RPT918

[37] FDA. GRAS Notice. GRN No. 30. Crospovidone-cranberry juice extract. ShanStar Biotech, Inc. Accessed September 6, 2019 at: https://www. accessdata.fda.gov/scripts/fdcc/index.cfm?set=GrASNotices\&id=30

[38] National Toxicology Program (NTP). Toxicology and carcinogenesis studies of quercetin (CAS No. 117-39-5) in F344 Rats (feed studies). Natl Toxicol Program Tech Rep Ser 1992; 409: 1-171

[39] International Agency for Research on Cancer (IARC). Quercetin. IARC monographs on the evaluation of carcinogenic risks to humans. Volume 73. World Health Organization (WHO). Accessed June 13, 2020 at: https://monographs.iarc.fr/wp-content/uploads/2018/06/mono73.pdf

[40] FDA. GRN No. 873. Cranberry Extract. Ocean Spray Cranberries, Inc. Date of closure May 6, 2020. Accessed January 8, 2021 at: https:// www.cfsanappsexternal.fda.gov/scripts/fdcc/index.cfm?set=GRAS Notices\&id=873\&sort=GRN_No\&order=DESC\&startrow=1\&type=basic \& search $=$ cranberry

[41] FDA. FDA announces qualified health claim for certain cranberry products and urinary tract infections. Constituent Update. Accessed July 21 , 2020 at: https://www.fda.gov/food/cfsan-constituent-updates/fda-announces-qualified-health-claim-certain-cranberry-products-and-urinary-tract-infections
[42] Natural Health Products Ingredients Database (NHPID). Health Canada. Accessed September 11, 2019 at: http://webprod.hc-sc.gc.ca/nhpidbdipsn/search-rechercheReq.do?lang=eng

[43] Health Canada. Cranberry-Vaccinium Macrocarpon. Health Canada Monograph. December 18, 2018. Accessed September 6, 2019 at: http://webprod.hc-sc.gc.ca/nhpid-bdipsn/atReq.do?atid=cranberry. canneberge\&lang=eng

[44] Health Canada. Dried cranberry juice. Health Canada Monograph. December 18, 2018. Accessed September 6, 2019 at: http://webprod. hc-sc.gc.ca/nhpid-bdipsn/atReq.do?atid=cranberry.dried.canneberge. deshydrate\&lang=eng

[45] Licensed Natural Health Products Database (LNHPD). Health Canada. Accessed September 11, 2019 at: https://www.canada.ca/en/healthcanada/services/drugs-health-products/natural-non-prescription/ applications-submissions/product-licensing/licensed-natural-healthproducts-database.html

[46] European Food Safety Authority (EFSA). Safety of cranberry extract powder as a novel food ingredient pursuant to regulation (EC) No 258/97. EFSA J 2017; 15: 4777

[47] French Agency for Food, Environmental and Occupational Health \& Safety. Opinion of the French Agency for Food, Environmental and Occupational Health \& Safety on the assessment of the potential effects of cranberry on community-acquired urinary tract infections. ANSES - Request no. 2010-SA-0214, March 18, 2011. Accessed September 1, 2019 at: https://www.anses.fr/en/system/files/NUT2010sa0214EN.pdf

[48] European Scientific Cooperative on Phytotherapy (ESCOP). Monograph on Vaccinii Macrocarpi Fructus (Cranberry). Accessed March 25, 2021 at: https://escop.com/escop-products/

[49] The Australian Register of Therapeutic Goods (ARTG). Australian Government Department of Health and Ageing. Accessed September 11, 2019 at: http://www.tga.gov.au/industry/artg.htm

[50] National Institutes of Health (NIH). The Dietary Supplement Labels Database (DSLD). Accessed September 11, 2019 at: https://dsld.od.nih.gov/ dsld/index.jsp

[51] American Botanical Council (ABC) Clinical guide to herbs. Cranberry Monograph. Accessed September 1, 2019 at: http://cms.herbalgram. org/ABCGuide/Monographs/Cranberry.html

[52] Wing DA, Rumney PJ, Preslicka CW, Chung JH. Daily cranberry juice for the prevention of asymptomatic bacteriuria in pregnancy: a randomized, controlled pilot study. J Urol 2008; 180: 1367-1372

[53] Essadi F, Elmehashi M. Efficacy of cranberry juice for the prevention of urinary tract infections in pregnancy [abstract]. Poster Session. (Study described in Ghouri et al. 2018). J Matern Fetal Neonatal Med 2010; 23 (S1): 378

[54] Ghouri F, Hollywood A, Ryan K. A systematic review of non-antibiotic measures for the prevention of urinary tract infections in pregnancy. BMC Pregnancy Childbirth 2018; 18: 99

[55] Haverkorn M], Mandigers J. Reduction of bacteriuria and pyuria using cranberry juice. J Am Med Assoc 1994; 272: 590

[56] Wang CH, Fang CC, Chen NC, Liu SS, Yu PH, Wu TY, Chen WT, Lee CC, Chen SC. Cranberry-containing products for prevention of urinary tract infections in susceptible populations: a systematic review and metaanalysis of randomized controlled trials. Arch Intern Med 2012; 172: 988-996

[57] Stapleton AE, Dziura J, Hooton TM, Cox ME, Yarova-Yarovaya Y, Chen S, Gupta K. Recurrent urinary tract infection and urinary Escherichia coli in women ingesting cranberry juice daily: a randomized controlled trial. Mayo Clin Proc 2012; 87: 143-150

[58] Ledda A, Belcaro G, Dugall M, Riva A, Togni S, Eggenhoffner R, Giacomelli L. Highly standardized cranberry extract supplementation (Anthocran) as prophylaxis in young healthy subjects with recurrent urinary tract infections. Eur Rev Med Pharmacol Sci 2017; 21: 389-393 
[59] Ledda A, Bottari A, Luzzi R, Belcaro G, Hu S, Dugall M, Hosoi M, Ippolito E, Corsi M, Gizzi G, Morazzoni P, Riva A, Giacomelli L, Togni S. Cranberry supplementation in the prevention of non-severe lower urinary tract infections: a pilot study. Eur Rev Med Pharmacol Sci 2015; 19: 77-80

[60] Ledda A, Belcaro G, Dugall M, Feragalli B, Riva A, Togni S, Giacomelli L. Supplementation with high titer cranberry extract (Anthocran) for the prevention of recurrent urinary tract infections in elderly men suffering from moderate prostatic hyperplasia: a pilot study. Eur Rev Med Pharmacol Sci 2016; 20: 5205-5209

[61] Singh I, Gautam LK, Kaur IR. Effect of oral cranberry extract (standardized proanthocyanidin-A) in patients with recurrent UTI by pathogenic E. coli: a randomized placebo-controlled clinical research study. Int Urol Nephrol 2016; 48: 1379-1386

[62] Juthani-Mehta M, Van Ness PH, Bianco L, Rink A, Rubeck S, Ginter S, Argraves S, Charpentier P, Acampora D, Trentalange M. Effect of cranberry capsules on bacteriuria plus pyuria among older women in nursing homes: a randomized clinical trial. JAMA 2016; 316: 1879-1887

[63] Valentova K, Stejskal D, Bednar P, Vostalova J, Cihalik C, Vecerova R, Koukalova D, Kolar M, Reichenbach R, Sknouril L, Ulrichova J, Simanek V. Biosafety, antioxidant status, and metabolites in urine after consumption of dried cranberry juice in healthy women: a pilot doubleblind placebo-controlled trial. J Agric Food Chem 2007; 55: 3217-3224

[64] Sengupta K, Alluri KV, Golakoti T, Gottumukkala GV, Raavi J, Kotchrlakota L, Sigalan SC, Dey D, Ghosh S, Chatterjee A. A randomized, double blind, controlled, dose dependent clinical trial to evaluate the efficacy of a proanthocyanidin standardized whole cranberry (Vaccinium macrocarpon) powder on infections of the urinary tract. Curr Bioact Compd 2011; 7: 39-46

[65] Madrigal-Santillán E, Fragoso-Antonio S, Valadez-Vega C, Solano-Solano G, Pérez CZ, Sánchez-Gutiérrez M, Izquierdo-Vega JA, Gutiérrez-Salinas J, Esquivel-Soto J, Esquivel-Chirino C, Sumaya-Martínez T, Fregoso-Aguilar T, Mendoza-Pérez J, Morales-González JA. Investigation on the protective effects of cranberry against the DNA damage induced by benzo[a]pyrene. Molecules 2012; 17: 4435-4451

[66] Palikova I, Vostalova J, Zdarilova A, Svobodova A, Kosina P, Vecera R, Stejskal D, Proskova J, Hrbac J, Bednar P, Maier V, Cernochova D, Simanek V, Ulrichova J. Long-term effects of three commercial cranberry products on the antioxidative status in rats: a pilot study. J Agric Food Chem 2010; 58: 1672-1678

[67] Chou HI, Chen KS, Wang HC, Lee WM. Effects of cranberry extract on prevention of urinary tract infection in dogs and on adhesion of Escherichia coli to Madin-Darby canine kidney cells. Am J Vet Res 2016; 77: 421-427

[68] Nowack R, Birck R. Cranberry products in the prevention of urinary tract infections: examining the evidence. Botanics 2015; 5: 45-54

[69] FDA. Center for Food Safety and Applied Nutrition (CFSAN) Adverse Event Reporting System (CAERS). Accessed September 11, 2019 at: https://www.fda.gov/food/complianceenforcement/ucm494015. htm\#FAQs

[70] Health Canada Adverse Reaction Online Database. Canada Vigilance Program. Accessed September 11, 2019 at: https://www.canada.ca/en/ health-canada/services/drugs-health-products/medeffect-canada/ canada-vigilance-program.html

[71] Database of Adverse Events Notifications (DAEN). Australian Government Department of Health Therapeutic Good Administration (TGA). Accessed September 11, 2019 at: https://www.tga.gov.au/databaseadverse-event-notifications-daen

[72] Medicines and Healthcare Products Regulatory Agency (MHRA) Yellow Card Database. Accessed September 11, 2019 at: https://yellowcard. mhra.gov.uk/idap
[73] European Medcines Agency (EMA). EudraVigilance. The European database of suspected adverse drug reaction reports. Accessed September 11, 2019 at: http://www.adrreports.eu/en/index.html

[74] Medsafe. New Zealand MedSafe suspected medicine adverse reaction search. Accessed September 11, 2019 at: https://medsafe.govt.nz/ Projects/B1/ADRSearch.asp

[75] Terris MK, Issa MM, Tacker JR. Dietary supplementation with cranberry concentrate tablets may increase the risk of nephrolithiasis. Urology 2001; 57: 26-29

[76] McHarg T, Rodgers A, Charlton K. Influence of cranberry juice on the urinary risk factors for calcium oxalate kidney stone formation. BJU Int 2003; 92: 765-768

[77] Light I, Gursel E, Zinnser HH. Urinary ionized calcium in urolithiasis. Effect of cranberry juice. Urology 1973; 1: 67-70

[78] Lynch DM. Cranberry for prevention of urinary tract infections. Am Fam Physician 2004; 70: 2175-2177

[79] Leahy M, Roderick R, Brilliant K. The cranberry-promising health benefits, old and new. Nutr Today 2001; 36: 254-265

[80] Xu C, Zhang C, Wang XL, Liu TZ, Zeng XT, Li S, Duan XW. Self-fluid management in prevention of kidney stones: a PRISMA-compliant systematic review and dose-response meta-analysis of observational studies. Medicine (Baltimore) 2015; 94: e1042

[81] Gettman MT, Ogan K, Brinkley LJ, Adams-Huet B, Pak CY, Pearle MS. Effect of cranberry juice consumption on urinary stone risk factors. J Urol 2005; 174: 590-594

[82] Kessler T, Jansen B, Hesse A. Effect of blackcurrant-, cranberry- and plum juice consumption on risk factors associated with kidney stone formation. Eur J Clin Nutr 2002; 56: 1020-1023

[83] Zinsser H, Seneca H, Light I, Mayer G, Karp F, McGeoy G, Tarrasoli H. Management of infected stones with acidifying agents. N Y State J Med 1968; 68: 301-310

[84] Aston JL, Lodolce AE, Shapiro NL. Interaction between warfarin and cranberry juice. Pharmacotherapy 2006; 26: 1314-1319

[85] Pham DQ, Pham AQ. Interaction potential between cranberry juice and warfarin. Am J Health Syst Pharm 2007; 64: 490-494

[86] Zikria J, Goldman R, Ansell J. Cranberry juice and warfarin: when bad publicity trumps science. Am J Med 2010; 123: 384-392

[87] Mellen CK, Ford M, Rindone JP. Effect of high-dose cranberry juice on the pharmacodynamics of warfarin in patients. $\mathrm{Br}$ J Clin Pharmacol 2010; 70 : 139-142

[88] Greenblatt DJ, von Moltke LL, Perloff ES, Luo Y, Harmatz JS, Zinny MA. Interaction of flurbiprofen with cranberry juice, grape juice, tea, and fluconazole: in vitro and clinical studies. Clin Pharmacol Ther 2006; 79: 125-133

[89] Grenier J, Fradette C, Morelli G, Merritt G], Vranderick M, Ducharme MP. Pomelo juice, but not cranberry juice, affects the pharmacokinetics of cyclosporine in humans. Clin Pharmacol Ther 2006; 79: 255-262

[90] Srinivas NR. Cranberry juice ingestion and clinical drug-drug interaction potentials; review of case studies and perspectives. J Pharm Pharm Sci 2013; 16: 289-303

[91] Mohammed Abdul MI, Jiang X, Williams KM, Day RO, Roufogalis BD, Liauw WS, Xu H, McLachlan AJ. Pharmacodynamic interaction of warfarin with cranberry but not with garlic in healthy subjects. $\mathrm{Br}$ J Pharmacol 2008; 154: 1691-1700

[92] Asher GN, Corbett AH, Hawke RL. Common herbal dietary supplementdrug interactions. Am Fam Physician 2017; 96: 101-107

[93] Bristol-Myers Squibb (BMS). Prescribing information for Coumadin (warfarin sodium). Revised August 2017. Accessed September 19, 2019 at: http://packageinserts.bms.com/pi/pi_coumadin.pdf 